\title{
DC compensation systems and their implications on the planning of expansions in Metro systems: a case study of Medellin
}

\author{
A. E. Díez ${ }^{1}$, P. Alzate ${ }^{1}$, J. V. Restrepo ${ }^{1}$, L. Castrillon ${ }^{2}$, \\ E. Manrique ${ }^{2} \&$ M. Figueroa ${ }^{1}$ \\ ${ }^{1}$ Universidad Pontificia Bolivariana, Colombia \\ ${ }^{2}$ Metro de Medellin, Colombia
}

\begin{abstract}
This paper describes DC compensation systems using as a reference the most important cases reported in literature, and a prototype designed and built for the Metro system of Medellin. Three functions and their implications on the planning and operation of transportation systems that operate with grid-connected vehicles are discussed. First, the energy saving feature that allows a reduction in energy consumption in the system, because less energy has to be dissipated in braking resistors. Second, the voltage compensation capability that allows that voltage level limits are fulfilled through the overhead line, to extend the operative range distance. Finally, the application for optimization of the electric feeding infrastructure is explained. In the case of the prototype installed in the Metro de Medellin, the methodology for siting, sizing, design and implementation is presented.

Keywords: static compensator, ultracapacitor, Metro system planning, efficiency, voltage regulation.
\end{abstract}

\section{Introduction: reference cases}

In the field of energy savings there are many references and developments of compensation systems demonstrating excellent results [1-3]. Similar to the case presented in this paper, Metro operators in Seoul, Daejon and Incheon [4] have achieved energy savings of more than $20 \%$ using ultracapacitor compensators. There are also several applications of energy storage systems involving 
ultracapacitors to allow the off-grid operation of mass transportation vehicles like streetcars, buses and trolleybuses $[5,6]$.

Cases to highlight of onboard applications for tramways are operating in Geneva (Switzerland), Guangzhou (China) and Sevilla and Zaragoza (Spain). It seems that ultracapacitors are becoming a standard component of the rolling stock in tramway systems.

For buses and trolleybuses, notable cases are Shanghai where a fleet of fast charging buses is under test, and the trolleybuses of Milan, Italy, where an ultracapacitor allows either off-grid operation of a few kilometers, and increased savings of braking energy. However, the best results correspond to those that combines the benefits of use the grid and the storage energy capability [7]. The worst results are the cases where a complete off-grid operation is pretended. Several ultracapacitor buses in Shanghai have caught fire [8], because of overheating caused by intensive use, avoiding overhead line support. The last condition is usually motivated for pressure against the visual pollution of overhead lines, wrongly put in counterbalance against more important concerns like air pollution and climate change.

As the field grows, research focuses on application of techniques like Neural Network and Genetic Algorithm to optimal placement and sizing of ultracapacitors in the Metro systems [9], when is required due the complexity of the network. There is also a lot of interest in improve or develop control strategies to maximize energy efficiency in systems that involves converters and energy storage devices $[10,11]$.

\section{Compensators as energy savers}

Compensation systems with energy storage capability are a good alternative to provide energy savings in transportation systems with electric traction mostly by competing with energy dissipation systems that are usually required to keep voltage within safety operational limits. Dissipative devices are based on resistors and, despite their voltage compensation effect; the energy radiated in form of heat cannot be recovered and become part of losses of the system.

On the other side is the train, which behaving as a fluctuating load, causing a voltage dip when is demanding power, and a voltage swell when braking. The magnitude of the voltage fluctuation depends on both the amount of power and the equivalent impedance of the system at the point of operation. The impedance increases with the distance to the energy sources that are traction substations. As the equivalent impedance becomes higher, the voltage fluctuation levels increases. To maintain a safety operation, voltage deviation has to be limited in a range among $20 \%$ over the nominal voltage and until $30 \%$ below, as defined in UNEEN 50163.

When the train is performing regenerative braking, it injects current into the system. Then, voltage rises, until safety threshold is reached. At that precise moment, the control system activates a dissipative device for braking in order to avoid damages due to overvoltage. 
The energy returned to the system could be used by trains that are in the same electric section for traction or auxiliary services, relatively close to the unit that is performing regenerative braking. This usually requires a synchronization between the accelerating and braking trains. When a train is demanding energy, the equivalent impedance of the system goes down, and the network increases its capability to receipt energy from braking trains. The level of acceptability of the system depends on the point of operation of the trains and the coincidence among power demand and regeneration (returns) of the trains. The amount of energy dissipated in form of heat will depend on the same variables. The above statements are true independently of the traction system of the trains, but former traction systems based on switchgear DC machines, controlled by choppers, tend to be less efficient, requiring greater dissipative braking.

Compensation systems allow for storage of braking energy instead of dissipating it as heat, when it is not possible to return it to the network. The stored energy could be used later by the same train or by other nearby trains. Depending on the topology of the network and other operational considerations, the energy storage system could be either installed onboard or placed stationary in a selected point of the feeding system.

An onboard energy storage system should be considered when an overhead line or third rail is not desired for esthetic reasons. Several tramway and trolleybuses systems incorporate onboard energy storage systems allowing off-grid operation for several kilometers. Also onboard systems appear to be a very good alternative in non-intensive operational schemes, where is convenient that the compensation moves along with the train.

When a weak point of the system needs reinforcement, a stationary solution tends to be more appropriate. In the case of Metro de Medellin compensation feature is more important that energy savings. However, the solution presented could represent energy savings of about $378 \mathrm{MWh}$ per year, with emissions savings of 75 Tons of $\mathrm{CO}_{2}$, considering the emission factor of the power system grid of Colombia.

Controllers based on choppers and DC-series machines, also requires preinsertion resistors to avoid high mechanical and electric transients when the train makes a transition between traction and braking. The last is the case of Metro de Medellin, where currently 42 units operate with the described control technique.

A simplified diagram of the traction system of the first generation trains of Metro Medellin allows finding possible energy savings by identifying dissipative elements such as resistors (fig. 1 shows both the pre-insertion and dissipation resistors). Using onboard measurement in combination with detailed simulation of the system, it was possible to estimate that dissipative losses in braking resistors represents, in average, $2 \%$ of the total energy consumed for traction, but in a remarkable finding, the energy dissipated into pre-insertion resistors results to be $17 \%$.

The problem is that static compensators only capture the energy of the braking resistors only, not the pre-insertion resistors. However, taking into account the potential savings, an onboard solution that store the energy instead the preinsertion resistors dissipation would be considered in the future. Also, a complete 


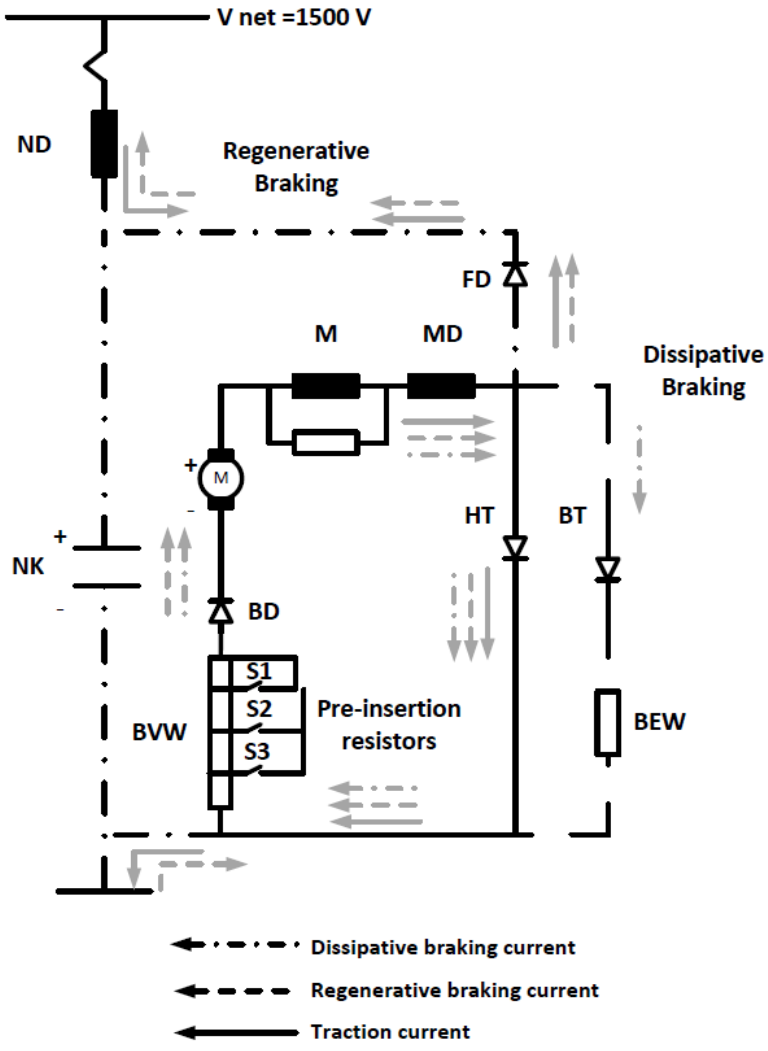

Figure 1: Simplified traction system of Metro de Medellin trains.

change of the traction chopper based on thyristors for a bilateral DC-DC Buck Boost converter based on modern IGBT would bring those and some additional benefits, such as the reduction of technology obsolescence risk.

Modern traction systems involving inverters and either induction or permanent magnet synchronous machines, have a similar behavior of DC drives, then compensators are still useful. AC drivers tend to be more efficient because preinsertion resistors are not needed and modern power electronic devices are capable to operate at higher frequencies, with low conversion losses.

\section{Compensators as voltage regulation systems}

As explained in section 2, the compensation feature is in many cases most important than energy savings. This feature has been explore in works like [4-7, 12].

Despite the fact that power source of the trains is designed to stand greater voltage fluctuation $(+20 \%,-30 \%)$, that ordinary equipment, this operating band 
limits either the longitude of the system and the amount of units able to operate in the same section at given system.

The magnitude of voltage fluctuations increases with the equivalent impedance of the system that rises along with the distance to traction substations. Usually the compliance of the operational voltage range is the constraint to extend a line, not the lack of power to supply the trains. At the same time, more trains operating in the same electric section, increase the possibility of coincidences of starting current demands, with the consequence of deepest voltage sags. Higher voltage swells also occur when several trains are braking at the same time in the same section.

Voltage compensation also brings collateral benefits as increase of equipment lifespan. Electronic equipment and insolation systems of electric machines are especially vulnerable to over-voltages.

\section{Case study: siting, sizing, design and implementation of a compensation system in the Metro of Medellin}

The flowchart of fig. 2 shows the methodology used to establish the status and needs of the power system of Metro de Medellin, based on the topological inspection in order to detect the electrically weakest points, usually located in the

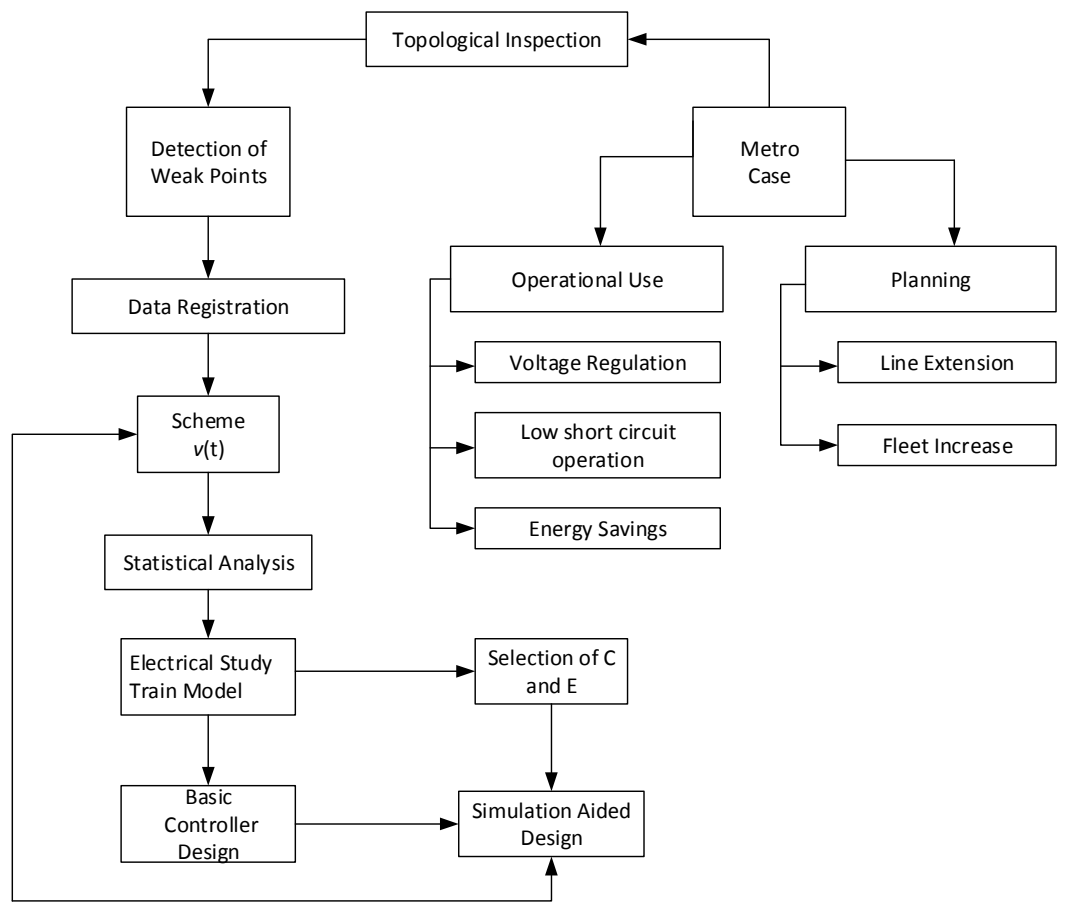

Figure 2: Flowchart of compensation application. 
"tail" of the system. In these points voltage profiles trends were recorded and statistically analyzed. Voltage fluctuations were characterized by their magnitude and time duration.

With this information, plus the required energy exchange of the system, a basic system with a Bidirectional DC/DC converter was calculated. Peak current, energy demand and system sensors were scaled and incorporated. The size of inductors, semiconductor switching devices, thermal management and control algorithms were developed.

The size of the compensator was calculated using the energy available when a train is braking. Mechanical and electric losses were estimated using computational simulation and extracted from the total energy. In the case of Metro de Medellin, the size of the storage device calculated, based on ultra-capacitors, is $4 \mathrm{kWh}$. However, a first prototype of $1 \mathrm{kWh}$ was designed and constructed to be expanded later in the future. Fig. 3 shows the protective relay used to the connection to the network (left), the converter (center) and the ultracapacitor bank (right).

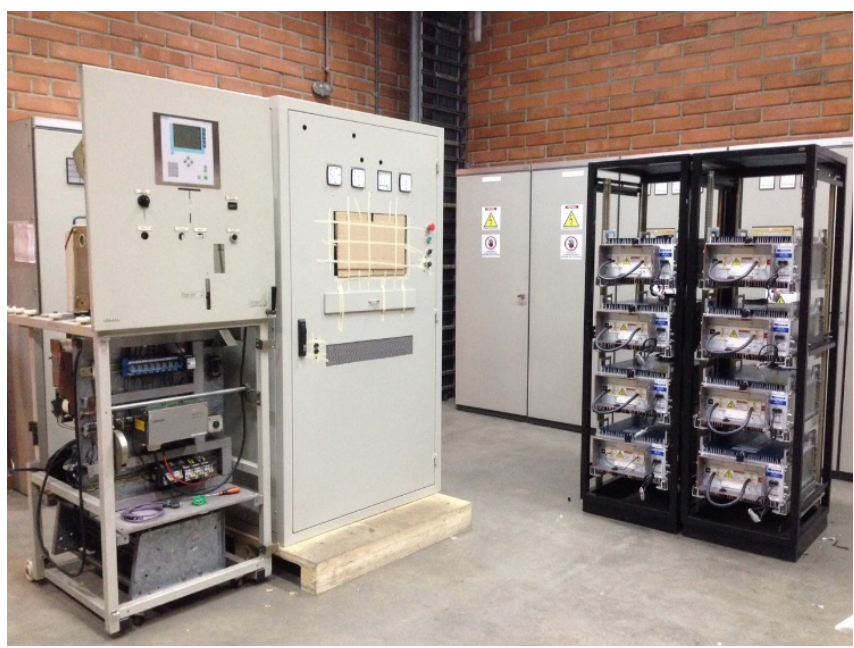

Figure 3: $\quad$ System prototype and ultracapacitor bank.

The last passenger station, Niquia, was selected as the installation point because is near to the extreme of the line and there is an expansion planed following this route to the north of the Aburra Valley. The distance between Niquia and the last traction substation is $2 \mathrm{~km}$. The need of voltage regulation forced to operate with both ascendant and descendent lines connected in parallel, increasing short circuit levels, and even in this condition, the upper limit of voltage is surpassed during $8 \%$ of the time. If a safe bandwidth between $1400 \mathrm{~V}$ and $1700 \mathrm{~V}$ is defined as the threshold to activate the compensator, it will operate during $30 \%$ of the time.

Eight ultracapacitor modules from the company Maxwell constitute the energy storage system. Each module is rated to $125 \mathrm{~V}$ with a capacitance of $63 \mathrm{~F}$. The maximum voltage of the 8 -module arrangement is $1000 \mathrm{~V}$, and the overall 
capacitance is $7,875 \mathrm{~F}$, for $1.094 \mathrm{kWh}$ of energy. The Specific Energy of the ultracapacitor used in the prototype is $2.3 \mathrm{kWh} / \mathrm{kg}$, the Usable Specific Power $1700 \mathrm{~W} / \mathrm{kg}$, and the projected life of 1 million cycles. The last two properties makes this device ideal for traction application over battery technology. Li-ion batteries, in contrast, have an energy density of around $150 \mathrm{kWh} / \mathrm{kg}$, but a discharge specific power of $300 \mathrm{~W} / \mathrm{kg}$ [13], less than the fifth part of the specific power of the ultracapacitor used.

The system stores a portion of braking energy during the twenty seconds that last the process, at an average power of $200 \mathrm{~kW}$, to deliver later at the same rate. A bilateral DC/DC Buck-Boost converter, triggered by voltage threshold, drives the energy flux from the system to the ultracapacitors and vice versa. The control design was described in a previous work [14]. This first prototype has been useful to develop skill and competences to the research team, in the field of power electronics and ultracapacitors. According to simulation and preliminary test results, using the compensation system would be possible to send a train service as far as $4 \mathrm{~km}$, without a new traction substation.

When complete, the equipment will have a rated power of $800 \mathrm{~kW}$ and will be able to store all the recover braking energy of train of Metro.

The cost of the ultracapacitor used was $51200 \mathrm{USD} / \mathrm{kWh}$, which is high when compared with Li-ion battery cost of $150 \mathrm{USD} / \mathrm{kWh}$. In this case, power capability and lifecycles are prevalent over energy.

\section{New planning paradigms}

Similar to their counterparts in electric power systems, compensation systems applied to electric transportation feeding systems, are traditionally conceived as mitigation devices. Compensation in power systems is used to keep the operating conditions in degraded circumstances such as voltage regulation in weak points, or to supply reactive power near to inductive loads.

Also in consonance to power system devices such FACTS (Flexible AC Transmission Systems) this kind of devices could quickly have an important role, from the conception, of future transportation systems.

It is expected that the compensator system will help to simplify the feeding infrastructure allowing delivering more energy to the vehicles, using the same installed capacity.

Difficulties in storing electric energy have shaped power systems. Transmission and distribution lines have to be sized to satisfy peak demands for few hours, remaining unloaded for the most part of the time. Electric generators have to be able to withstand maximum peak demand even if its duration is only few seconds. This instantaneous nature of the conversion and consumption of electric energy is the reason to conceive the electric network as a power system, instead of an energy system [15].

However, recent developments in batteries and other energy storage systems such ultracapacitors, those based in hydrogen, among others, are reshaping power systems into energy systems. The need for incorporate renewable energy into the grid is also pushing hard this transition, given the natural fluctuations of 
the resources like wind and solar radiation. In this scenario, the same transmission lines, and electric equipment in general, rated to peak demands, will be able to deliver and transport greater amounts of energy, simply by operating near to rate power, for more time. The energy would be delivered at a high constant rate to consumption centers where the excess received in hours of valley demand, would be stored to use in peak times.

The infrastructure of electric transportation system feeding would be reshaped similar to power systems, maybe sooner than expected, because of the particularities of its operation. Applications in this field would be easier to escalate and replicate due the high levels of controllability and knowledge of the equipment involved.

Trains, trams, trolleybuses have to operate in a predesigned schedule, following either rules or commands from an operator, very different to the randomly, unpredictable and difficult to control, power system usual consumers.

From the point of view of the demand, transportation rolling stock represents also the fluctuating load for excellence, with high starting currents, low demand at steady speed and energy regeneration. Onboard applications have probe to be also useful to reduce peak demand from the feeding system [7], again, this allows fleet expansion using the same infrastructure.

For these reasons power networks involving mass transportation systems are the best laboratory to begin the transition from power system to energy systems. Achievements reached in these grids would be easy to extrapolate to large power systems.

A planning application considering compensation systems from the beginning, could be the expansion of lines, differing high investments until the consolidation of the new route.

With a compensator, the line would be expanded an important distance until reaching new towns or interest sites, with fulfillment of voltage requirements, if some few units are used for the exploitation of the line. It is common to have low passenger demand in the first years of operation. When passenger demand and train use reaches the point where the compensator is unable to keep voltage regulation, the device is replaced by a traction substation. The compensation would be moved to another point of the line, to be use in a new extension, or to reinforce a weak point in other place of the system.

Financial benefits from postponing investments like those in traction substations are important in order to reduce the overall cost of the project. This cost is the main reason argued to prefer systems like Bus Rapid Transit to a Metro solution, despite the cheaper solution is foreseeable to become saturated in the midterm. The train line of Metro of Medellin has been extended only $2 \mathrm{~km}$ to the south in 15 years. For this extension a new traction substations was required, with a cost of 7 Million USD. A compensator with a cost of 1 Million USD along with one substation would be enough to achieve operational conditions. Fig. 4 presents the scheme of the purposed extension.

For the extension to the north, a solution considering the use of a compensator and a traction substation is under study, instead of two traction substations. The 
project will extend the system $4.5 \mathrm{~km}$ to the north of the valley. An upgraded system of the one under test now would be used.

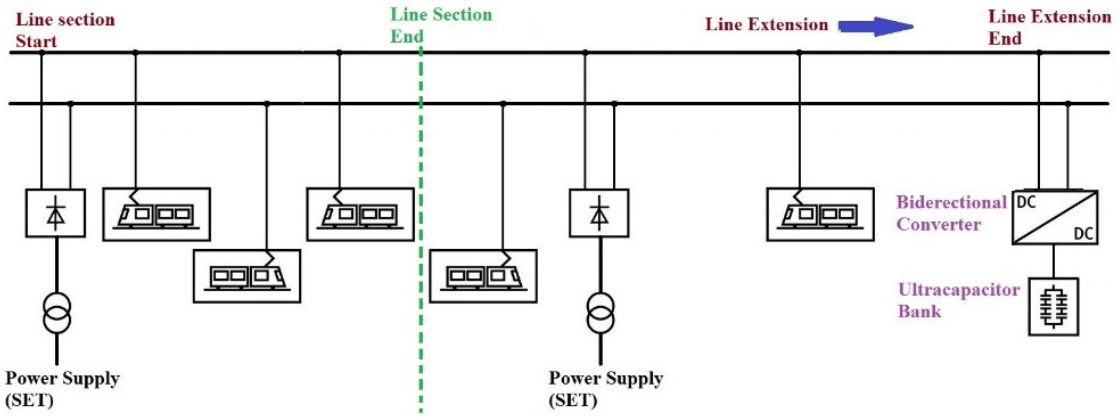

Figure 4: Extension of the line using ultracapacitor compensation.

\section{Conclusions}

The fast expansion of electrified railway systems is a need for undeveloped countries, but infrastructure cost is still one of the main barriers to these projects.

Compensators including state-of-the-art devices such as ultracapacitors have opened a very important field of applications to improve energy management and use of infrastructure. They would detonate the transition from power system to energy systems. This transition is likeable to start into systems to feed electric transportation network, and then expanded to large power systems. The knowledge and experience developed in this field would be very important to develop control techniques to deal with variable demand and energy supply, which is the challenge of the integration of renewable energy.

As infrastructure cost is one of the most important barriers to implementing systems based on electric traction vehicles, such as Metro and tramways lines, a strategy to reduce initial capital cost, by using temporally auxiliary compensators is suggested. This could allow deferring some years larger investments like those in traction substation, as the systems is gradually expand in either longitude or fleet.

There is a need for research to improve the control strategies of converters and make them more versatile and easy to integrate to any network. Also, would be interesting the development smart systems able to change automatically parameters like switching frequency, according to site characteristics and operational circumstances.

\section{Acknowledgement}

This work was also supported by COLCIENCIAS "Sistema de compensación en corriente directa para aprovechamiento de frenado regenerativo basado en ultracapacitores" with code 1210-5623-6307. 


\section{References}

[1] Ciccarelli, F., Iannuzzi, D \& Tricoli, P., Control of metro-trains equipped with onboard supercapacitors for energy saving and reduction of power peak demand. Transportation Research Part C: Emerging Technologies, pp. 36-49, 2012.

[2] Iannuzzi, D. \& Tricoli, P., Metro trains equipped onboard with supercapacitors: a control technique for energy saving. Power Electronics Electrical Drives Automation and Motion (SPEEDAM), 2010 International Symposium on. IEEE, 1, pp. 750-756, 2010.

[3] System For Supplying Very Low Voltage Electrical Energy For An Electrical Traction Vehicle Comprising An Onboard Store Of Energy, Patent Application US20070278059 A1. Online http://www.google.com/ patents/US20070278059

[4] Ultracapacitor energy storage offers metro operators $20 \%$ savings, Railway Gazette, Online http://www.railwaygazette.com/news/news/asia/singleview/view/ultracapacitor-energy-storage-offers-metro-operators-20savings.html

[5] Hoimoja, H., Vinnikov, D. \& Jalakas, T., Analysis and design of ultracapacitor-boosted back-up power supply for tramcars. EUROCON 2009, EUROCON'09. IEEE. IEEE, 1, pp. 583-589, 2009.

[6] Diab, Y., Evaluating Performance and Reliability of Storage System with Supercapacitors: Application in Trolleybuses, Damascus University Journal, 30(1), pp. 47-48, 2014.

[7] Thounthong, P., Sikkabut, S., Mungporn, P. \& Piegari, L., DC bus stabilization of Li-Ion battery based energy storage for hydrogen/solar power plant for autonomous network applications, Industry Applications Society Annual Meeting, 2014 IEEE. 1, pp. 1-8, 2014.

[8] Chinese Electric Bus Catches Fire On Road, Not The First One, Gren Car Reports, Online. http://www.greencarreports.com/news/1063473 chineseelectric-bus-catches-fire-on-road-not-the-first-one

[9] Kashani, S.J. \& Farjah, E, Applying neural network and genetic algorithm for optimal placement of ultra-capacitors in metro systems, Electrical Power and Energy Conference (EPEC), 2011 IEEE, 1, pp. 35-40, 2011.

[10] Ciccarelli, F., Iannuzzi, D., \& Spina, I, Comparison of energy management control strategy based on wayside ESS for LRV application, Industrial Electronics Society, IECON 2013-39th Annual Conference of the IEEE, 1, pp. 1548-1544, 2013.

[11] Calderaro, V., Galdi, V., Graber, G. \& Piccolo, A, Siting and sizing of stationary SuperCapacitors in a Metro Network, AEIT Annual Conference, 1, pp. 1-5, 2013.

[12] Iannuzzi, D., Pagano, E. \& Tricoli, P, The use of energy storage systems for supporting the voltage needs of urban and suburban railway contact lines. Energies, 6(4), pp. 1802-1820, 2013. 
[13] Chalk, Steven G. \& James F. Miller, Key challenges and recent progress in batteries, fuel cells, and hydrogen storage for clean energy systems, Journal of Power Sources, 159(1), pp. 73-80, 2006.

[14] Killer, A., Armstorfer, A., Diez, A.E. \& Biechl, H, Ultracapacitor assisted regenerative braking in metropolitan railway systems, Intelligent Transportation Systems Symposium (CITSS), 2012 IEEE Colombian. IEEE, 1, pp. 1-6, 2012.

[15] Gómez-Expósito, A., Conejo, A. \& Cañizares, C. (eds). Electric energy systems: analysis and operation. CRC Press, 2008. 